\title{
Injúria renal e hemorragia em paciente vítima de acidente botrópico: relato de caso
}

\author{
Renal injury and hemorrhage in a patient victim of a botropic accident: case report \\ Lesión renal y hemorragia en paciente víctima de accidente botrópico: reporte de caso
}

Ketllyn de Oliveira Cruz ${ }^{1,2 *}$, Wilson de Oliveira Filho ${ }^{1,2}$, Soraya Souto da Silva ${ }^{1,2}$, Bruna Lyandra Portela Sena de Souza ${ }^{1,2}$, Rafaelly Taketomi de Magalhães ${ }^{1,2}$.

\section{RESUMO}

Objetivo: Relatar um caso de paciente vítima de acidente ofídico, no estado do Amazonas, em 2020, onde a vítima apresentou quadro grave de injúria renal e hemorragia. Detalhamento de Caso: Paciente do sexo feminino, em um município do Amazonas com história de acidente ofídico, por Jararaca (Bothrops sp), internada em hospital para tratamento, evoluiu com injúria renal aguda e distúrbio de coagulação, hemodinamicamente estável, mas com presença de extrassístoles ventriculares. Apresentou anúria, motivo pelo qual foram iniciadas sessões de hemodiálise. Devido à gravidade das hemorragias e do quadro renal, no $10^{\circ}$ dia pós acidente optou-se pela readministração de soro antiofídico, em 12 ampolas, que a dose indicada no paciente grave. O Quadro clínico apresentou melhora e as extrassístoles ventriculares desapareceram no $11^{\circ}$ dia de internação, mas a paciente permaneceu realizando sessões de hemodiálise. Considerações finais: Os relatos de casos de acidentes ofídicos são de grande relevância para fornecer premissas para desenvolvimentos de futuros protocolos de tratamento. Infelizmente os acidentes ofídicos são uma realidade rotineira na Amazônia e a busca por atendimento médico deve ser feita de imediato, podendo essa ser a diferença entre um resultado positivo e um prognóstico ruim.

Palavras-chave: Acidente ofídico, Envenenamento, Bothrops.

\begin{abstract}
Objective: To report a case of a patient victim of an ophidian accident, in the state of Amazonas, in 2020, where the victim presented severe renal injury and hemorrhage. Case Details: Female patient, from the municipality of Amazonas with a history of snakebite, by Jararaca (Bothrops sp), admitted to a hospital for treatment, developed acute kidney injury and coagulation disorder, hemodynamically stable, but with presence of ventricular extrasystoles. He had anuria, which is why hemodialysis sessions were started. Due to the severity of the hemorrhages and the renal condition, on the 10th day after the accident, we opted for the readministration of anti-ophidic serum, in 12 ampoules, than the dose indicated for critically ill patients. The clinical picture improved and the ventricular extrasystoles disappeared on the 11th day of hospitalization, but the patient remained undergoing hemodialysis sessions. Final considerations: Ophidian accident case reports are of great relevance to provide premises for the development of future treatment protocols. Unfortunately, snakebite accidents are a routine reality in the Amazon and the search for medical care must be done immediately, which can be the difference between a positive result and a bad prognosis.
\end{abstract}

Key words: Snakebite accident, Poisoning, Bothrops.

\section{RESUMEN}

Objetivo: Informar el caso de un paciente víctima de accidente ofídico, en el estado de Amazonas, en 2020, donde la víctima presentó lesión renal severa y hemorragia. Detalle del caso: Paciente de un municipio de Amazonas con antecedente de mordedura de serpiente, por Jararaca (Bothrops sp), ingresada en un hospital para recibir tratamiento, desarrolló lesión renal aguda y trastorno de la coagulación, hemodinámicamente estable, pero con presencia de extrasístoles ventriculares. Tenía anuria, por lo que se iniciaron sesiones de

\footnotetext{
${ }^{1}$ Hospital Pronto Socorro 28 de Agosto, Manaus - AM. *E-mail: ketllyn_cruz@hotmail.com

2 Hospital Universitário Getúlio Vargas, Manaus - AM.
}

SUBMETIDO EM: 12/2020

ACEITO EM: 1/2021

PUBLICADO EM: 2/2021 
hemodiálisis. Debido a la severidad de las hemorragias y a la condición renal, al décimo día después del accidente optamos por la readministración de suero antiofídico, en 12 ampollas, a la dosis indicada para pacientes críticos. El cuadro clínico mejoró y las extrasístoles ventriculares desaparecieron al 11ำ día de internación, pero el paciente permaneció en sesiones de hemodiálisis. Consideraciones finales: Los informes de casos de accidentes ofidianos son de gran relevancia para proporcionar premisas para el desarrollo de futuros protocolos de tratamiento. Lamentablemente, los accidentes por mordedura de serpiente son una realidad rutinaria en la Amazonía y la búsqueda de atención médica debe realizarse de inmediato, lo que puede ser la diferencia entre un resultado positivo y un mal pronóstico.

Palabras clave: Accidente por mordedura de serpiente, Envenenamiento, Bothrops.

\section{INTRODUÇÃO}

Os acidentes ofídicos, popularmente chamados de "picadas de cobra", são um sério problema de saúde nos países tropicais (AMORIM FG, et al., 2017), muitas vezes negligenciado em países de continentes subdesenvolvidos, como África, Ásia, América Latina e Oceania (ALVES EC, et al., 2018). Os venenos de serpentes são secreções compostas por moléculas biologicamente ativas, capazes de desencadear efeitos locais e sistêmicos nas vítimas de envenenamento (MAMEDE CCN, et al., 2020).

Diversos venenos de serpentes, como os do gênero Bothrops (popularmente chamadas de jararacas, cotiaras e urutus), apresentam importantes efeitos locais que nem sempre são neutralizados de forma eficiente pela soroterapia convencional. Consequentemente, esses acidentes podem resultar em sequelas permanentes e incapacidades, gerando problemas econômicos e sociais, principalmente nos países em desenvolvimento, chamando a atenção da Organização Mundial da Saúde que considera o envenenamento ofídico uma doença tropical negligenciada (BARALDI PT, et al., 2016).

Dados de 2018 estimavam cerca de 1.800 .000 casos e 94.000 mortes anualmente no mundo em decorrência desses acidentes (ALVES EC, et al., 2018). Dados mais recentes, da Organização Mundial da Saúde, estimam 2,7 milhões de acidentes ofídicos com humanos anualmente no mundo. Nesse panorama global de incidência de ofidismo, o Brasil é o terceiro país, junto ao Vietnã, em número de acidentes com serpentes peçonhentas no mundo, atrás apenas de Índia e Sri Lanka (MATOS RR e IGNOTTI E, 2020).

No Brasil, dados do Sistema de Informação de Agravos de Notificação (SINAN) de 2015 relataram 15.454 casos de envenenamento com taxa de letalidade estimada em 0,4\%. Apenas no estado do Amazonas, ocorrem em média 1.500 acidentes ofídicos por ano, resultando em uma taxa de incidência de 52,8 casos por 100.000 habitantes, cuja proporção de letalidade é superior à taxa nacional de 0,6\% (ALVES EC, et al., 2018).

No Brasil, o gênero Bothrops (família Viperidae) é o causador da maioria desses acidentes, que se caracterizam por proteólise e hemorragia (AMORIM FG, et al., 2017). A Lesão Renal Aguda (LRA) é a complicação sistêmica mais significativa e causa de morte por envenenamento por serpentes da família Viperidae. Na Amazônia, a espécie mais importante é Bothrops atrox (jararaca comum, jararaca amazônica, jararaca e localmente como surucucu) geralmente encontrada em áreas florestadas e povoadas (ALVES EC, et al., 2018). Além disso, o veneno das espécies de Bothrops spp. contém metaloproteinases, que contribuem para os efeitos vasculares e hemorrágicos graves (DELGADO ABT, et al., 2017).

O tratamento é baseado na administração de anticorpos purificados, produzidos pela hiperimunização de animais (geralmente equinos) para geração de imunoglobulinas (Igs), e então obtidos pelo fracionamento do plasma hiperimune. Produz-se assim os antivenenos, que são preparações de imunoglobulinas (Igs), ou fragmentos de Ig, como $F(a b) 2$ ou Fab. Os antivenenos geralmente são muito eficientes para neutralizar os efeitos sistêmicos mais relevantes do envenenamento ofídico. Os entraves terapêuticos podem ser devidos ao início precoce desses efeitos, bem como à má distribuição das Igs e seus fragmentos nos tecidos locais onde o veneno é injetado. Além disso, a administração de antiveneno pode estar associada, em percentual variável de casos, a reações adversas precoces e tardias às proteínas heterólogas (GOMES M, et al., 2019).

Além disso, as serpentes do gênero Bothrops têm venenos compostos principalmente por enzimas proteolíticas. Assim, embora o soro antibotrópico (produzido pelo Instituto Butantan) seja notável em salvar 
vidas, estudos mostram que alguns sintomas observados em casos de envenenamento não são neutralizados com eficácia (KUNIYOSHI AK, et al., 2019).

O uso de anticorpos recombinantes é uma alternativa ao tratamento convencional do envenenamento ofídico, principalmente o fragmento $\mathrm{Fv}$, denominado fragmento variável de cadeia única $(\mathrm{scFv})$. Essas moléculas apresentam várias características distintivas quando comparadas ao anticorpo inteiro, como maior difusão para os tecidos afetados, baixa imunogenicidade, eliminação mais rápida e menor formação de imunocomplexos (GOMES M, et al., 2019).

Do ponto de vista da gestão em saúde, estudos de incidência de acidentes ofídicos são essenciais para otimizar o atendimento à vítima, minimizando a gravidade e garantindo o sucesso do tratamento e o treinamento contínuo do pessoal médico envolvido pode ajudar a otimizar o atendimento ao paciente e evitar subnotificação no sistema de notificação de acidentes. Sabe-se, por exemplo, que esses acidentes são provavelmente influenciados pelas mudanças climáticas e atividades humanas (COSTA MKB, et al., 2019).

Mas existe uma lacuna nos dados epidemiológicos devido às falhas de notificação, o que tornam as informações sobre as manifestações clínicas em casos graves muito importantes, reforçando-se a relevância de serem relatadas com precisão (DELGADO ABT, et al., 2017).

Mas a literatura nesse tema ainda é considerada escassa, o que reforça a importância da divulgação de casos clínicos como o desse estudo, de uma paciente vítima de acidente botrópico, no estado brasileiro do Amazonas. Assim, esse estudo teve por objetivo trazer o relato desse caso clínico, onde a vítima apresentou quadro grave de injúria renal e hemorragia, relatando sua evolução e tratamento realizado, no intuito de colaborar com dados para a literatura sobre o tema.

\section{DETALHAMENTO DO CASO}

Paciente do sexo feminino, 48 anos de idade, domiciliada em um município do Amazonas com história de acidente ofídico, por Jararaca (Bothrops sp.), identificada pela própria paciente, no ano 2020. Apresentavase em bom estado geral, consciente e orientada. A lesão foi em pé esquerdo, com evolução de dor e edema local, sem sinais de necrose. Foi internada no hospital local, onde foram administradas 4 ampolas de soro antiofídico e esquema de ATB, com gentamicina e clindamicina (Figura 1).

Figura 1 - Lesão em pé esquerdo por acidente botrópico.

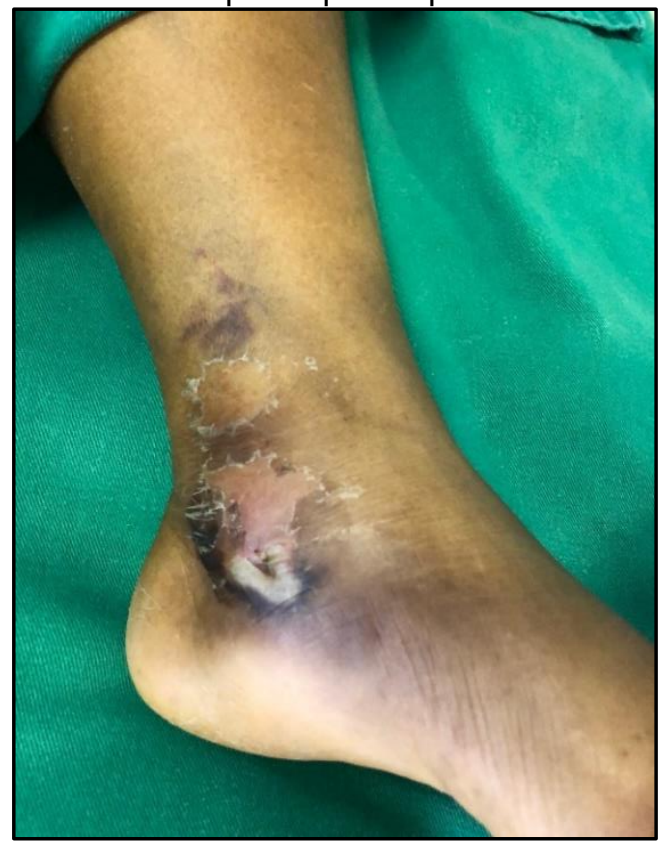

Fonte: Cruz KO, et al., 2020. 
Transferida para leito de unidade de terapia intensiva (UTI) em hospital na capital de Manaus no dia seguinte, evoluiu com injúria renal aguda e distúrbio de coagulação, hemodinamicamente estável. Sem história patológica pregressa. Passou a apresentar anúria, motivo pelo qual foram iniciadas sessões de hemodiálise. Foi evidenciado, também, desde a internação, a presença de extrassístoles ventriculares (Figura 2).

Figura 2 - Eletrocardiograma onde se observam extrassístoles ventriculares.

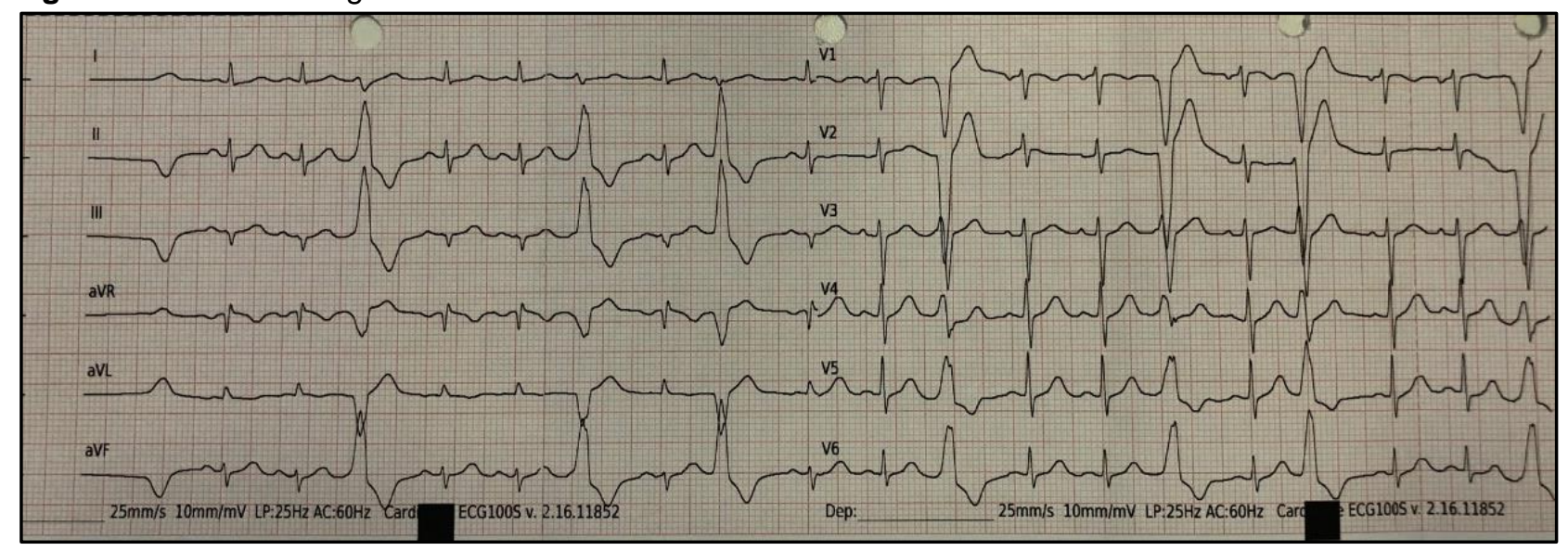

Fonte: Cruz KO, et al., 2020.

Laboratorialmente, apresentava inicialmente a razão normalizada internacional (INR) de 6,9, com posterior melhora e queda progressiva de plaquetas, chegando a $45.000 \mathrm{mg} / \mathrm{dl}$. No $3^{\circ}$ dia de internação evoluiu com desconforto respiratório importante, sendo então necessária a intubação orotraqueal.

Devido a persistência de sangramento por via aérea superior, vaginal e hemorragia digestiva alta, no $10^{\circ}$ dia pós acidente optou-se então pela readministração de soro antiofídico, dessa vez 12 ampolas, que é padronizada como a dose indicada no paciente grave. No mesmo dia cessaram-se os sangramentos. As extrassístoles ventriculares desapareceram no $11^{\circ}$ dia de internação. Permaneceu realizando sessões de hemodiálise.

\section{DISCUSSÃO}

De acordo com Alves EC, et al. (2018), o veneno do gênero Bothrops é composto por uma complexa mistura de peptídeos e proteínas biologicamente ativas que induzem uma ampla gama de efeitos. As manifestações locais e/ou sistêmicas ocorrem em decorrência da lesão tecidual com posterior liberação de mediadores inflamatórios e alterações no sistema de coagulação e fibrinolítico. Diante disso, as vítimas de envenenamento frequentemente apresentam uma intensa resposta inflamatória aguda com dor, edema, rubor, sangramento, hematomas e bolhas no local da picada, conforme pode ser verificado na paciente deste relato. Os efeitos sistêmicos, que também foram observados na paciente, são cefaleia, náuseas, vômitos, hemorragia espontânea (gengival, nasal, digestiva, hematúria, hematêmese) e, mais raramente, coagulação intravascular disseminada e choque.

Segundo Mamede CCN, et al. (2020), os danos locais mais comuns são a inflamação, com consequente ativação celular e liberação de mediadores inflamatórios, hemorragia, edema, dor e (mio)necrose, podendo levar à amputação das áreas afetadas. No caso da paciente desse relato, apesar da reação local ter sido intensa, com grave hematoma e edema, não foi caso de amputação, pois não se observou necrose.

Alves EC, et al. (2018) alertam que podem ocorrer complicações devido a fatores clínicos e ambientais e incluem, além da necrose e risco de amputação, infecção secundária, Lesão Renal Aguda (LRA), hemorragia intracraniana, síndrome compartimental e até mesmo situações infrequentes, como descolamento de placenta em mulheres grávidas e hematoma hepático. A LRA foi observada na paciente do presente relato, o que agravou bastante seu quadro clínico, levando-a a necessitar de sessões de hemodiálise. 
Alves EC, et al. (2018) explicam que a LRA ocorre devido às toxinas do veneno terem ação renal direta, alterando sua estrutura e fisiologia devido à vulnerabilidade capilar. Além disso, ocorre Necrose Tubular Aguda, que é a causa mais comum de LRA no envenenamento por acidente ofídico. Segundo os autores, estudos experimentais associam esse dano a fatores como gênero e distribuição geográfica da serpente, gravidade do acidente, tempo de exposição ao veneno e quantidade inoculada de veneno. A patogênese da LRA ainda não foi totalmente elucidada, porém, é proposta uma origem multifatorial onde alguns fatores desencadeantes atuariam de forma combinada ou isolada. Entre esses fatores estão distúrbios hemodinâmicos com sangramento ou depósito de fibrina em estruturas tubulares, processos inflamatórios, formação de imunocomplexos e ação nefrotóxica do veneno.

Cabe destacar, como ensinam Moura-da-Silva AM, et al. (2020), que os venenos das serpentes são misturas complexas de proteínas com atividades tóxicas, com diversas isoformas distintas, compreendidos em poucas famílias de proteínas, mas que afetam diferentes alvos fisiológicos, como é o caso do sistema renal.

De acordo com Alves EC, et al. (2018), o desenvolvimento de LRA após envenenamento ofídico tem sido associado à idade do indivíduo, onde as crianças são mais propensas devido à área de superfície inferior do corpo, idade da cobra, composição do veneno e mecanismo de ação das toxinas, tempo decorrido entre o acidente e a administração do antiveneno e a presença de comorbidades como diabetes mellitus e hipertensão, que têm sido associadas à LRA nesses pacientes. Nesse caso, é importante destacar que a distância até as instalações médicas se torna um grande obstáculo na Amazônia, uma vez que as vítimas precisam percorrer longas distâncias até os serviços de saúde, estando sujeitas a complicações devido às peculiaridades geográficas.

Ademais, conforme explicam Mota da Silva A, et al. (2019), na região amazônica, os acidentes ocorrem principalmente em áreas florestais, quintais de casas em áreas rurais e próximas a ambientes aquáticos, durante as atividades humanas, como caminhadas, serviços de lavoura, extrativismo ou caça. Na maioria das vezes, a serepente se encontra no chão e a picada ocorre por aproximação do indivíduo, seja por pisoteio ou por aproximação de uma mão. Outro dado importante é que metade das vítimas realiza algum tipo de primeiros socorros inadequados, o que não se sabe se foi o caso da paciente desse estudo, pois tal informação não se encontrava em seu histórico.

Existe, na literatura, relatos de complicações menos comuns relacionadas com acidentes botrópicos, como a trazida por Delgado ABT, et al. (2017), de uma paciente que mesmo recebendo tratamento com soro antiBothrops evoluiu com piora da consciência, distúrbios da fala e hemiparesia do lado esquerdo, onde o exame neurológico mostrou um escore de coma de Glasgow de 14, o que significa uma lesão cerebral traumática leve.

Em outros dois casos, descritos por Sachett J, et al. (2020), os pacientes que apresentaram hemorragia subaracnoidea com hidrocefalia e hemoventrículo, sendo que ambos os casos também ocorreram no estado do Amazonas, assim como o caso da paciente desse estudo, porém seu caso não chegou a apresentar esse tipo de sintomatologia. Em ambos os casos do estudo de Sachett J, et al. (2020), os pacientes apresentaram retardo na administração da soroterapia, o que pode ter contribuído para o surgimento das complicações, como $o$ acidente vascular cerebral (AVC).

O paciente 1 foi internado no hospital 16 horas após o acidente, desenvolvendo AVC hemorrágico (hemorragia subaracnóidea com hidrocefalia e hemoventrículo). No sétimo dia recebeu alta hospitalar. Já o paciente 2 chegou ao hospital três dias após o acidente e apresentou sangue não coagulado, AVC (hemorragia frontoparietal direita, hemorragia intraparenquimatosa já aberta para o ventrículo) e morreu no oitavo dia. Portanto, reforça-se que o atraso na procura de cuidados de saúde após o envenenamento por serpentes pode culminar em prognósticos piores.

Essas variações nos quadros sintomatológicos podem ser derivadas de diferenças nas composições dos venenos, conforme explicam Del-Rei THM, et al. (2019), que analisaram os venenos de espécies de $B$. atrox três regiões geográficas diferentes da Amazônia brasileira e encontraram diferenças funcionais notáveis, particularmente entre os venenos de duas populações separadas pelo rio Amazonas. De acordo com os 
autores, um dos tipos avaliados induziu dermonecrose mais forte, mas foi menos pró-coagulante e letal para camundongos, enquanto outro foi mais hemorrágico, matou camundongos com mais eficiência, mas induziu menores sinais de dermonecrose.

Estudos têm sido desenvolvidos no sentido de desenvolver novos compostos para o tratamento de envenenamento ofídico, como o de Baraldi PT, et al. (2016), que produziram um inibidor eficiente contra venenos botrópicos, ao sintetizarem diferentes moléculas classificadas como quinolinonas (grupo de compostos químicos de baixa toxidade amplamente utilizados como antibacterianos e antimicobacterianos) e e testarem suas propriedades inibidoras contra hemorragias causadas por esses venenos. Os resultados indicaram que a molécula 2-hidroximetil-6-metoxi-1,4-di-hidro-4-quinolinona (Q8) foi o composto antihemorrágico mais eficaz entre todas as quinolinonas sintéticas testadas, sendo capaz de inibir significativamente as atividades hemorrágicas e/ou proteolíticas de venenos brutos botrópicos e metaloproteases de veneno de serpentes isoladas, mesmo em concentrações mais baixas. Portanto, tanto os dados experimentais quanto os estruturais indicam que o composto Q8 é um candidato interessante para terapia antiofídica, particularmente para o tratamento dos efeitos hemorrágicos e necróticos induzidos por venenos botrópicos.

Produtos derivados de plantas também têm sido pesquisados, tendo em visto que o Brasil possui muitas comunidades tradicionais que utilizam plantas no tratamento de envenenamento ofídico. No estudo de Corrêa AL, et al. (2019), por exemplo, foram testados os perfis fitoquímicos e a capacidade dos extratos das folhas de Myrsine parvifolia em reduzir o processo inflamatório (edema, aumento da permeabilidade vascular e migração de leucócitos) induzido pelo veneno de Bothrops jararaca, in vivo. Os resultados do estudo indicaram quehá uma potencial atividade antiinflamatória de $M$. parvifolia na intoxicação por B. jararaca, principalmente na redução dos efeitos venenosos locais.

Em outro estudo, Salvador GHM, et al. (2019) avaliaram o uso de ácido acetilsalicílico e de um composto vegetal com propriedades antiofidianas, o ácido rosmarínico. Seus resultados indicaram que o ácido rosmarínico é capaz de prevenir os efeitos miotóxicos e que permanece fortemente ligada à toxina, enquanto as moléculas do ácido acetilsalićlico tendem a se dissociar. Esta abordagem auxilia na concepção de inibidores eficazes de toxinas ofídicas podem complementar a terapia com soro.

Diante do caso aqui apresentado e dos dados fornecidos pelos autores consultados, pode-se verificar a importância dos relatos de casos de acidentes ofídicos, pois há sitomatologias diferentes apresentadas, e suas descrições, bem como os cuidados utilizados, são de relevância para a comunidade científica, para fornecer premissas para desenvolvimentos de futuros protocolos de tratamento. Infelizmente os acidentes ofídicos são uma realidade rotineira na Amazônia e a busca por atendimento médico deve ser feita de imediato, podendo essa ser a diferença entre um resultado positivo e um prognóstico ruim.

\section{REFERÊNCIAS}

1. ALVES EC, et al. Predicting acute renal failure in Bothrops snakebite patients in a tertiary reference center, Western Brazilian Amazon. PLoS One, 2018; 13(8): e0202361.

2. AMORIM FG, et al. New findings from the first transcriptome of the Bothrops moojeni snake venom gland. Toxicon, 2017; 140: 105-117.

3. BARALDI PT, et al. A novel synthetic quinolinone inhibitor presents proteolytic and hemorrhagic inhibitory activities against snake venom metalloproteases. Biochimie, 2016; 121: 179-188.

4. CORREAA AL, et al. Protective effect of Myrsine parvifolia plant extract against the inflammatory process induced by Bothrops jararaca snake venom. Toxicon, 2019; 157: 66-76.

5. COSTA MKB, et al. Snake bite accidents in Rio Grande do Norte state, Brazil: Epidemiology, health management and influence of the environmental scenario. Tropical Medicine \& International Health, 2019; 24(4): 432-441.

6. DELGADO ABT, et al. Hemorrhagic stroke secondary to Bothrops spp. venom: A case report. Toxicon, 2017, 132: 68.

7. DEL-REI THM, et al. Functional variability of Bothrops atrox venoms from three distinct areas across the Brazilian Amazon and consequences for human envenomings. Toxicon, 2019; 164: 61-70. 
8. GOMES M, et al. Expression of an ScFv antibody fragment in Nicotiana benthamiana and in vitro assessment of its neutralizing potential against the snake venom metalloproteinase BaP1 from Bothrops asper. Toxicon, 2019; 160: 3846.

9. KUNIYOSHI AK, et al. Experimental antivenom against serine proteases from the Bothrops jararaca venom obtained in mice, and its comparison with the antibothropic serum from the Butantan Institute. Toxicon, 2019; 169: 59-67.

10. MAMEDE CCN, et al. Edema, hyperalgesia and myonecrosis induced by Brazilian bothropic venoms: Overview of the last decade. Toxicon, 2020; 187: 10-18.

11. MATOS RR, IGNOTTI E. Incidência de acidentes ofídicos por gêneros de serpentes nos biomas brasileiros. Ciência \& Saúde Coletiva, 2020, 25(7): 2837-2846.

12. MOTA DA SILVA A, et al. Ethno-knowledge and attitudes regarding snakebites in the Alto Juruá region, Western Brazilian Amazonia. Toxicon, 2019; 171: 66-77.

13. MOURA-DA-SILVA AM, et al. The relationship between clinics and the venom of the causative Amazon pit viper (Bothrops atrox). PLoS Neglected Tropical Diseases, 2020, 14(6): e0008299.

14. SACHETT J, et al. Cerebrovascular accidents related to snakebites in the Amazon - two case reports. Wilderness \& Environmental Medicine, 2020; 31(3): 337-343.

15. SALVADOR GHM, et al. Search for efficient inhibitors of myotoxic activity induced by ophidian phospholipase A2-like proteins using functional, structural and bioinformatics approaches. Scientific Reports, 2019; 9(1): 510. 